\title{
Capacity-building for health research in developing countries: a manager's approach
}

\author{
Franklin White ${ }^{1}$
}

ABSTRACT Research may be viewed as rigorous inquiry to advance knowledge and improve practices. An international commission has argued that strengthening research capacity is one of the most powerful, cost-effective, and sustainable means of advancing health and development. However, the global effort to promote research in developing countries has been mostly policy driven, and largely at the initiative of donor agencies based in developed countries. This policy approach, although essential, both contrasts with and is complementary to that of research managers, who must build capacity "from the ground up" in a variety of health service settings within countries and with differing mandates, resources, and constraints. In health organizations the concept of research is broad, and practices vary widely. However, building research capacity is not altogether different from building other kinds of organizational capacity, and it involves two major dimensions: strategic and operational. In organizations in the health field, if reference to research is not in the mission statement, then developing a relevant research capacity is made vastly more difficult. Research capacities that take years to develop can be easily damaged through inadequate support, poor management, or other negative influences associated with both internal and external environments. This paper draws from key international research policy documents and observations on the behavior of research and donor agencies in relation to developing countries. It examines capacity-building primarily as a challenge for research managers, realities underlying operational effectiveness and efficiency, approaches to resource mobilization, and the need for marketing the research enterprise. Selected examples from South Asia and Latin America and the Caribbean are presented.

Key words Research, developing countries, health resources, health manpower, staff development.

Building research capacity is similar to building other kinds of organizational capacity. A utilitarian definition of research is simply "rigorous inquiry to increase knowledge and improve

\footnotetext{
1 The Aga Khan University, Department of Community Health Sciences, Karachi, Pakistan, and also Dalhousie University, Department of Community Health \& Epidemiology, Halifax, Nova Scotia, Canada. Send correspondence to: Franklin White, Department of Community Health Sciences, The Aga Khan University, Stadium Road, PO Box 3500, Karachi 74800, Pakistan; e-mail: franklin.white@aku.edu
}

practices." In management terms, building such a capacity reflects a commitment to "quality improvement" and characterizes a "learning organization" (1). Health research is therefore best viewed as a broad and robust concept that includes not only biomedical and clinical research but also epidemiological and related community health research, health systems research, health services research, operational research, and so on. Research is also implicit within other functions: planning, evaluation, surveillance, investi- gation, problem analysis, and external audit. In this holistic sense, research is as basic to effective and efficient health care as financing.

Effectiveness and efficiency in health services were highlighted in the 1970s by Archie Cochrane in his analysis of the British National Health Service (2). In the 1980s "health as a resource" was recognized in the health promotion movement (3), and "investing" in this resource by the World Bank in 1993 (4). This evolution reflected the growing recognition of an "evidence-based" ap- 
proach to health issues, especially as applied to policy, programmatic, and clinical decision-making.

According to a 1990 report of the international Commission on Health Research for Development (5), "strengthening research capacity in developing countries is one of the most powerful, cost-effective, and sustainable means of advancing health and development." That this applies to countries at all stages of development is illustrated by the World Health Organization European Regional Office statement in 1997 that "there is little research-based evidence about the components of effective hospital management" (6).

The challenge of promoting health research in developing countries was recently addressed by the Global Forum on Health Research (7), with particular origins in the international perspective of the United Nations and other development agencies. However, this approach is mostly policydriven and contrasts with (although it's complementary to) that of the research manager, who must build capacity "from the ground up" within a given context. Furthermore, like all managers, the research manager must manage change, for example, adjusting the capacity of a research organization to the rapidly evolving patterns of health and disease, such as the emergence of the AIDS pandemic and the now-burgeoning impact of noncommunicable diseases in virtually all developing countries.

\section{CAPACITY-BUILDING}

In addressing research capacitybuilding, there are two main levels: strategic and operational. The strategic level is more fundamental because, in order to be effective operationally, one must first be sure of the philosophical basis and must operate within a strategic framework.

\section{The strategic management context}

Like other good management practices, "rigorous inquiry to increase knowledge and improve practices" must come from the top. The quality of management can make or break research capacity. This starts with a vision and/or mission statement. For example, during the early 1990s, the Caribbean Epidemiology Center (CAREC) developed the following mission statement, which explicitly includes a commitment to research (8):

To advance the health status of Caribbean people by advancing the capabilities of member countries in epidemiology, laboratory technology and related public health disciplines through technical cooperation, service, training, research and a well-trained motivated staff.

Illustrating a similar commitment from South Asia, the Aga Khan University (AKU) President's Order number 3 states (9):

Whereas His Highness Prince Karim Aga Khan and the Aga Khan Foundation have established in Pakistan a Health Sciences Complex whose programs will promote human welfare in general and the welfare of the people of Pakistan in particular and have expressed the desire to establish an autonomous University ... for the promotion and dissemination of knowledge and technology and for providing instruction, training, research, demonstration and service in the health sciences...

Departments may also have mission statements, and in Community Health Sciences at Aga Khan University this is:

To train young people for leadership in addressing health problems of the people of Pakistan, particularly those of the more deprived populations, through the primary care approach, and to contribute to improvements in the health services of Pakistan, particularly through the development of prototypes that are effective and affordable.

Planning cycles flow from mission statements, and the cycles incorporate goals, objectives, strategies, action plans, monitoring, and evaluation. In turn, they lead to the periodic revision of goals and objectives. This "management cycle" applies to organizations, systems within organizations, and particular functions within those systems. If reference to research is not in the mission statement (at least implicitly), developing a relevant research capacity is made vastly more difficult.

In developing countries one often hears that the health sector cannot develop research due to a lack of managerial support, time, and funding. If we look carefully, we may also find little or no reference to research in mission statements. Some organizations may not even have a statement. Developing or revising a mission statement enables the role of research to be addressed or updated and will help to develop a learning organization.

\section{Prioritizing research}

Responsibility for developing a research-friendly environment applies beyond health issues to public policy as a whole, and it brings us to the issue of priorities, which is also relevant to capacity-building. National priorities for education and for health servicesincluding related research-are reflected in the level of public sector investment, especially when compared with other expenditures or with countries experiencing similar resource constraints. All of the countries of South Asia spend far more on their military establishments than on health, while the converse holds for Latin America (10). For example, in India and Pakistan during the period of 1996-1998, public expenditures on health were, respectively, only $0.6 \%$ and $0.8 \%$ of gross domestic product (GDP) while military spending amounts were, respectively, $2.1 \%$ and $4.2 \%$ of GDP. This was in sharp contrast to the nations of Latin America, where the median expenditure on health was $2.5 \%$ of GDP and on the military was $1.25 \%$ of GDP. The only exception in Latin America is Colombia, with military spending being $2.6 \%$ of GDP in this period and health outlays being $1.5 \%$ of GDP. While Colombia's share for health is below the median for Latin America, it 
is still double the health investment level of India and Pakistan. It is therefore little wonder that the health situation in the countries of Latin America and the Caribbean compares favorably, reflecting to a large extent the higher priority given to investment in health over the decades.

In health policy forums a shift towards a greater use of evidence from research is being urged, with an emphasis on optimizing health benefits and promoting equity (11). There is also a critical need for more broadly based participation in this process as an increasingly important political and managerial dimension (12). However, just as global priorities are not synonymous with national priorities, neither are national priorities synonymous with local or institutional ones. Each level requires its own process and is subject to a differing set of realities.

This principle can be illustrated with two examples, one from the Global Fund to Fight AIDS, Tuberculosis and Malaria and the other from the Commission on Macroeconomics and Health. The Global Fund reflects a continuing emphasis on programming for a few diseases deemed to be global priorities (13). However, in many countries of Latin America and the Caribbean (LAC), and even of South Asia, these conditions are not of equivalent public health concern. For example, malaria is of little consequence in many LAC countries, while the impact of AIDS in Pakistan is so far very small. In both Asian and LAC countries diarrheal disease is still widely endemic. In all those nations, attention must be given to more than just two or three diseases.

The Commission on Macroeconomics and Health advocates "essential interventions," an approach that implicitly requires mostly top-down decisions, with little reference to building local capacity (14). Both the Global Fund and the Commission cases emphasize the "disease to poverty" pathway, which holds that people who become ill are downwardly mobile economically, so that investing in disease prevention is a form of poverty alleviation. This view, understandably, is strongly advocated by organizations that seek greater financial allocations, especially for global programs oriented towards "priority diseases." The alternative model, of "poverty to disease," requires at least equal emphasis on local actions, and it is more firmly established in the scientific literature. It is clear therefore that the public health research agenda in developing countries must not be left up to the international community to prescribe, and that it is the responsibility of the countries themselves to define their priorities. In this sense the global agenda is complementary at best. Developing countries themselves must build their systems more assertively in accordance with self-determined needs and with their own resources.

To foster research at national and subnational levels, appropriate structures are required. For example, at the national level, many countries have a medical research council. In large countries such as Brazil, Canada, and India there may also be a need to develop similar structures at the provincial or state level. At the other extreme there is a need to consolidate this kind of guidance capacity, such as with the countries of the West Indies, which have pooled their capabilities and created the Caribbean Health Research Council (formerly the Commonwealth Caribbean Medical Research Council). Universities that aspire to research within their mission, in turn, must have a research office to facilitate skills development, grant opportunities, peer review, and linkages.

However, research capacities that take years to develop can easily be destroyed through inadequate support or poor management. Capacities can also be damaged by shifting policies of international granting agencies (especially when projected as instruments of foreign policy), by the political directions of countries, and by unresponsive bureaucracies at any level. Examples of this can be found in the histories of both Asian and LAC countries. To build effective structures and functions requires investment of vision, time, and energy, steadily working towards progressively more complex challenges built upon initial successes.

\section{The operational context}

The most critical element in any enterprise is usually the human resource. Building an effective team requires good operational management, in which members share the mission and the commitment to a self-correcting cycle, and have the right mix of skills to ensure success. This requires wellthought-out post descriptions, attractive recruiting strategies, and criteria for appointment and promotion, thus ensuring that appropriate people are hired and promoted. Performance appraisal systems must be keyed to realistic and evolving expectations, mutually negotiated between each team member and the team leader.

Having just outlined an ideal approach, let us note some common realities: the promotion of people to jobs for which they are inadequately qualified, and the assignment of people to posts for which their training is underutilized or is not recognized. There is a better way.

The paradigm of good practices is shifting from a synthesis of pathophysiological concepts, experience, and common sense to one that increasingly recognizes scientific evidence as its foundation. The education of health professionals now requires the discipline of "keep on asking, keep on searching, keep on learning" (15). Unfortunately, however, many physicians still practice the medicine of their year of graduation rather than moving with the times (16). How then can one promote the discipline of lifetime learning? This major aim of professional education requires the capacity to critically read and understand scientific literature, to incorporate what is relevant into practice, and to discard outmoded approaches. For example, an undue dependence on textbooks must be replaced by a greater reliance on journals, MEDLINE searches, and the intelligent use of the Internet. Future health professionals must exercise independent judgment and must have the capacity 
to assess and apply in their practices relevant evidence derived from research. In other words, commitment to research in health care must be not only top-down but also bottom-up.

Exposure to research oriented to relevance, impact, and quality improvement must be instilled within professional education systems. For example, at the Aga Khan University we expose medical students to the self-correcting cycle shown in Figure 1. All students are also required to carry out a research project, usually community-based, during their education. In this way the culture of research and development as inherent qualities of health care systems is inculcated. While this approach is the norm in many developed countries, in many developing country settings the more traditional emphasis on rote learning rather than discovery through problem-based learning still predominates. That must be changed.

The development of research skills generally requires additional, postgraduate education. This is an area in which Pakistan offers an interesting model to the world, by requiring a dissertation for medical specialty certification and thereby exposing young physicians to the challenge of research. This may be compared with the M.D. thesis option in some Commonwealth of Nations countries, such as at the University of the West Indies, which has campuses located in three countries: Barbados, Jamaica, and Trinidad and Tobago. Other options-not limited to physicians - are to do a postgraduate research degree requiring a thesis at the master's or doctoral level. There is no single ideal model, and skills may also be developed through relevant short courses with project requirements.

In the end, candidates learn that research requires rigorous preparation and significant time and effort. Even before a competitive grant is obtained for research, dozens or even hundreds of hours might go into formulating a proposal. In spite of that effort, only a minority of submissions succeed. Once the proposal is funded, it must be executed. If one fails to deliver, the likelihood of future funding from the same

FIGURE 1. The health system as a self-correcting cycle

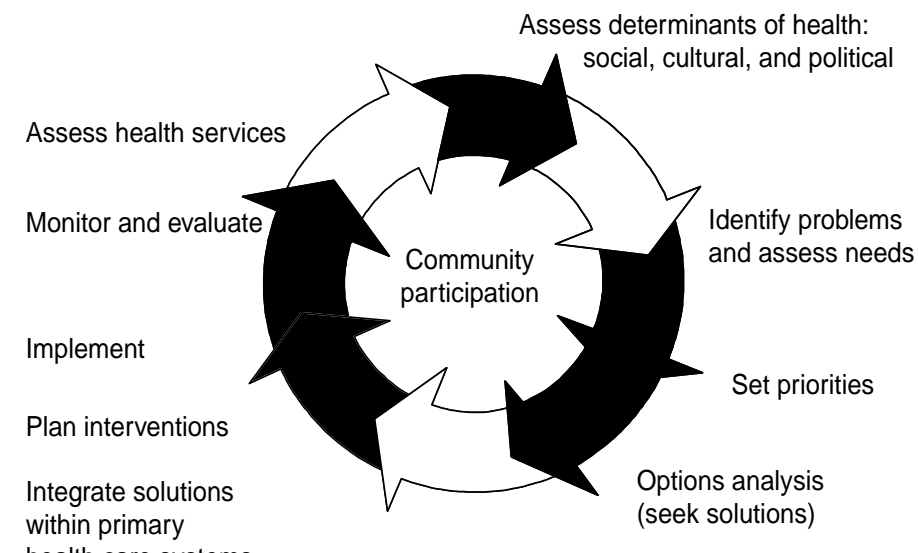

health care systems

source will decline. These are stressful issues, for which there is a great need to encourage young researchers to grow professionally, through mentoring and the recognition of accomplishments.

\section{The research manager}

To develop research managers, research training alone is not enough. Equal attention must go to the managerial dimension, including skills in such areas as risk analysis, priority-setting, planning, budgeting, human relations, team-building, and developing incentives and rewards. Not all researchers are destined to become research managers, and it may be hazardous to promote a brilliant researcher into this role if he or she is not a competent manager. Based largely on charisma or sometimes their political connections, a few may succeed, although not necessarily with happy teams.

In the management of research, the four classical planning steps apply. The first is a situation analysis, the second is setting goals and objectives, the third is an action plan, and the fourth is monitoring and evaluation. After assessing the situation, one can identify needs, recognize the gaps, and develop goals and objectives and an action plan to close those gaps. In turn, monitoring and evaluation are required for accountability. To appoint as a research manager an individual unwilling to proceed along these lines is to risk acting on the "Peter Principle," that is, to promote people to their level of incompetence (17).

The most important task of the research manager is to create an atmosphere of freedom from fear of intelligent failure as well as acceptance of uncertainty as an inevitable ingredient. This must be understood elsewhere in the organization, including the offices of the chief executive officer, of personnel, and of finance. Each of these offices must be flexible and creative in order to be supportive. While productivity cannot be measured in the same way as in other kinds of work, researchers may be assessed for their contribution to the advancement of relevant knowledge and improvements in practices. Research outputs in themselves are not necessarily enough to justify the investment, and efforts are needed to disseminate and promote applications at relevant levels of policy and practice.

Ensuring that the products of research are relevant is where the Essential National Health Research (ENHR) concept serves as a model, by linking research to national priorities, policies, and programmatic applications (18). Now advocated in all regions of the world, including LAC and South Asia, the principle is to link research with development needs, which is equally 
relevant to regional, provincial, local, and institutional levels, although needs and priorities are not synonymous across these levels. In developing country contexts, is it useful to use the combined term "research and development" (R\&D), in order to maintain our emphasis on this relationship. In some organizations the critical linkage between these two concepts may be explicit even in the name of the organization, as in the case of the Center of Experimental and Applied Endocrinology, which is located in La Plata, Argentina, and focuses on research on diabetes quality of care (19).

There are some excellent guides for developing health research, such as a manual for priority-setting using the ENHR strategy available from the Council on Health Research and Development (18), and a health systems research (HSR) training series available from the International Development Research Centre, in Canada. The latter includes content on HSR as a management tool, strategies for promoting HSR among policymakers and senior managers, and the training of managers of research institutes, academic departments, and agencies with supporting and coordinating roles.

\section{Resource mobilization}

Research is not necessarily a costly venture; to the contrary, if the goal is quality improvement, it should be highly cost-effective. For example, case reports and program reviews mostly involve examining and writing up observations in a critical manner. Program reviews, which are usually conducted without additional funding and are a function primarily of good management practices, can stand up well as contributions to the public health literature (20). Literature reviews also require little funding. Process analyses are now routinely conducted by many institutions, and some have stood up well as examples of quality-of-care research (21). Even some forms of field research can be relatively inexpensive, especially if little laboratory support is required, such as with case-control studies based on questionnaire-derived data (22). Time and money are often interchangeable. The only caveat is that methodological rigor is required. In other words, with a supportive mission and trained personnel, even with little or no explicit funding, individuals and institutions can conduct research. To a large extent, therefore, having at least a basic research capacity is a matter of choice.

Making a start on research capacitybuilding with minimal financial investment is different from building research at a level that can become a national or regional resource, which may involve a major amount of planning and development. Realistically, most developing country health care organizations cannot aspire to this, but all countries must ensure that there are at least some centers within their environment with the mission of making such a contribution. In building capacity, one examines not only priorities (national, provincial, regional) but also "mandate" and "comparative advantage." For example, product regulation is normally a national matter, and it thus stands to reason that there should exist a national research capacity to support this role. In contrast, one should not normally expect a university hospital to develop regulatory research, especially as conflict may arise with the competing need for rapid laboratory response to support patient care, which is the primary goal.

\section{Developing viable grant submissions}

A key ingredient in building research capacity is the development of grant-writing skills. While formal training takes care of the basics, there is no limit to the amount of practice in order to become more effective over time. Grant-writing workshops can expand research activity in an institution, lift standards of internal peer review, and stimulate attention to the requirements of granting agencies, thereby increasing the chances of success. Research is a demanding process, and the development of intramural and small grant programs can help to promote the necessary skills and resilience.

The human side of research is key, and it is important to recognize and support talent and enthusiasm. This is true even if the area of research interest is not initially necessarily a systemdetermined priority. A recently published study on diabetes in Bolivia (23) is a case in point. Much of the original "push" for this study came from the involvement of a young representative of the Bolivian Diabetes Society in a regional training course on diabetes epidemiology, which itself was a project of a nongovernmental organization (NGO), the Latin American Diabetes Epidemiology Group, in cooperation with external partners. This in turn led to considerable networking efforts, involving the World Health Organization (WHO), the Pan American Health Organization (PAHO), the Government of Bolivia, and leading Bolivian NGOs. The end result of this partnership was a key diabetes prevalence survey on adults in four major cities of Bolivia (23).

However, good submissions can sometimes be rejected because they do not fit the established priorities of the organization or the nation, and in this lies the potential shortcomings of priority-setting, including whose priorities are addressed and how adequate the process is. Some priorities are influenced by the "latest fashion," and some may be "donor driven," with the potential to distort national or local priorities. While sound, some proposals may not be funded for reasons such as strong competition for limited funds. Some poorly constructed proposals will be approved because they fit the official priorities list. On some occasions groups will be funded simply because they are well established and not necessarily because they put forward the best proposals. Good proposals from lesser-known institutions and individuals may be viewed as risky. In the end, however, unless there is some return to the researcher in terms of recognition and funding, there will be a brain drain, either out of the geographic area or out of research itself to other occupations perceived as more 
rewarding; rather than "capacity-building," this is "capacity-destroying."

From time to time, grant flows diminish due to external factors beyond the control of investigators. In these situations, other strategies can be used to maintain capacity. Among the possibilities are to revert to activities that require little or no funding, solicit smaller grants or contracts, seek a more diverse range of funding sources, pool resources with partners, and undertake certain kinds of consulting contracts that may offer value similar to a small grant. Some institutions may be able to develop the capacity for bridge financing, with a budget provision to underwrite, at least for a defined period of time, the continued employment of people supported by extrabudgetary funds. This can ensure that these persons are not automatically released at the end of an external grant or contract. This measure can be key in seeing that skills that are needed for future opportunities are not lost and that research capacity painstakingly built up over time is not destroyed overnight due to unanticipated external forces. One can use the time creatively to develop more-ambitious grant submissions that may be viable once the funding freeze lifts, or submit these to previously uninvolved agencies. For example, during the 12-15 months immediately following Pakistan's change to military government in October 1999, and the consequent withdrawal of funding by many international agencies, the AKU Department of Community Health Sciences sustained a 30\% decline in the value of research and development support, but simultaneously doubled the actual number of grants and contracts (smaller, shorter in duration, and more often locally acquired), increased publications output, and maintained research capacity by using all these approaches. New grants acquired during the early part of 2001 have subsequently restored the previous funding level, while the situation post-September 11 confronts us with a new kind of challenge: how to absorb the newfound international interest in funding projects in this now "politically correct" but impoverished part of the world!

\section{Governance as a critical success factor}

Even if a given unit secures external grant funding, not all organizations will be governed in a manner that will result in the desired overall capacitybuilding. In fact, there are many organizations throughout the world where the acquisition of such funds may result in a reduction of core budget, with the balance being transferred to other, less-efficient units of the organization. In the case of internationally supported operations, the funding may be shifted to other institutions less well managed, an instance of the rule that "the squeaky wheel gets the grease." While justified in some situations, this phenomenon may also reflect complex political motivations to restrict development, and it is ultimately a disincentive to the research manager and the staff of the organization.

One of the key risks during times of grant instability is opportunism, that is, taking whatever comes along without full consideration of its merits. Equally, there is a danger of exploitation by some agencies that might perceive that a weakened organization will have lost negotiating power, and they will set about to create relationships that are stacked in favor of the funding agency or that may not meet the usual norms. For example, perhaps by coincidence, an international agency donor recently backed out of a potential relationship with AKU after the donor was advised that their proposal would have to be submitted to local scientific and ethical review. To avoid these risks, it is critical to be true to one's mission.

Once capacity is developed and matures, a local resource may become a national or even an international one. At AKU, for example, projects elsewhere in Asia and in Africa are now considered. These help to broaden experience, maintain capacity, and buffer periods when viable opportunities within Pakistan become restricted, such as recently. The best-known example of this process in South Asia is the International Centre for Diarrhoeal Disease Research, which is in Bangladesh. In the Americas, the historical development of the Caribbean Epidemiology Center (CAREC) from its origins as a national arbovirus laboratory to a $\mathrm{PAHO} / \mathrm{WHO}$ center with multicountry membership is another case in point (24). Also illustrating this principle elsewhere in Latin America and the Caribbean are a number of other specialized $\mathrm{PAHO} / \mathrm{WHO}$ centers, such as the Institute of Nutrition of Central America and Panama and the Latin American Center for Perinatology and Human Development.

According to Roussel et al. (25), there are some important management rules related to resource mobilization:

- Research projects are never "sacred"; projects must sometimes be suspended or terminated when conditions render them unfeasible or when better proposals arise.

- Time given to unsuccessful ventures cannot be recovered and can be an opportunity cost, that is, the cost to passing up one opportunity in favor of another.

- Just as in financial investments, one should not "throw good money after bad."

- Good ideas require attention anytime, not just at budget time.

- There should be no projects in the "nothing better to do" category.

- There should be "overbooking"; that is, one should make more submissions than the capacity to implement them strictly allows, on the assumption that not all attempts to generate funds for research will succeed.

- Contracting out and partnerships are always an option for enhancing capacity.

\section{The marketing of research}

How can we encourage our national leaders to recognize the importance of building research capacity? Unless this is achieved, there is little likelihood that national priorities for research on health-related areas will greatly change. Similarly, at other levels in the health, social, and educational sectors, a necessary part of the solution are chief ex- 
ecutive officers (CEOs) (using this term in its most inclusive sense, to denote the most senior person in executive or decision-making authority in any organization, regardless of its type). However, now consider a quote from our corporate cousins reported by Roussel et al. (25): “CEOs actually devote only trivial amounts of their time and energy to these early stages [of research and development]. Instead, they typically have significant involvement only during production and marketing-when it's too late to do anything that can influence the outcome [of the enterprise]."

CEOs have a major influence on the environment and destiny of the institutions that they head. R\&D should be part of their preparation, but many current CEOs have risen to their positions without this advantage. There- fore, a special effort must be made to bring research priorities, activities, and outputs to their attention. This is no less true for heads of government and for ministers of health and social sectors. Similar actions are needed at other levels. For example, in most developing countries, district health officers are the health "CEOs" for very large populations, entailing major responsibility for resource management for primary health care, which requires its own $R \& D$ effort.

The critical role of the CEO notwithstanding, the foregoing comments should not be taken as "letting the researcher off the hook." Researchers and research managers have an obligation to publish their findings in relevant journals. To the extent that their work has more immediate relevance, researchers must also communicate with the public through press releases and other tools, and directly with the political and decision-making constituencies. This requires both developing a dissemination plan and following through with the plan.

Research may be viewed as rigorous inquiry to advance knowledge and improve practices. Strengthening research capacity is a requirement for any organization that aspires to advance the quality, relevance, and impact of its services. Building research capacity requires paying as much attention to good management practices as to the research itself.

Acknowledgments. Debra Nanan critically reviewed successive drafts of this paper, and Kausar Khan contributed the utilitarian definition of research.

\section{REFERENCES}

1. Senge PM. The fifth discipline: the art and practice of the learning organization. New York: Doubleday; 1990.

2. Cochrane AL. Effectiveness and efficiency: random reflections on health services. London: The Nuffield Provincial Hospitals Trust; 1972.

3. White F. Epidemiology in health promotion: a Canadian perspective. Bull Pan Am Health Organ 1989;23:384-396.

4. The World Bank. World development report 1993: investing in health. New York: Oxford University Press; 1993.

5. The Commission on Health Research for Development. Health research: essential link to equity in development. New York: Oxford University Press; 1990.

6. World Health Organization. European health care reform: analysis of current strategies. Copenhagen: World Health Organization Regional Office for Europe; 1997. (WHO Regional Publications, European Series, No. 72).

7. Global Forum on Health Research. The 10/90 report on health research 1999. Geneva: World Health Organization; 1999.

8. Caribbean Epidemiology Centre. CAREC mission statement. Available at: http://www. carec.org/about/index.html. Accessed $8 \mathrm{Au}-$ gust 2001.

9. The Aga Khan University. President's order no. 3. Karachi, Pakistan: The Aga Khan University; 1983.

10. United Nations Development Program. Human development report 2000. New York: Oxford University Press; 2000.
11. Working Group on Priority Setting, Council on Health Research for Development. Priority setting for health research: lessons from developing countries. Health Policy Plan 2000; 15(2):130-136.

12. White F. De la evidencia al desempeño: cómo fijar prioridades y tomar buenas decisiones. Rev Panam Salud Publica 1998:4:69-74.

13. World Health Organization. The Global Fund to Fight AIDS, Tuberculosis and Malaria. Available at: http://www.who.int/directorgeneral/global_fund/globalfundsummary. en.html. Accessed 12 July 2002.

14. World Health Organization. Macroeconomics and health: investing in health for economic development. Report of the Commission on Macroeconomics and Health. Geneva: WHO; 2001.

15. Espallardo NL, Leopando ZE. Evidence based family practice and quality improvement in health care. Manila: The National Center for Quality Excellence and Research in Family Practice; 2000.

16. Sackett DL, Haynes RB, Tugwell P. Clinical epidemiology: a basic science for clinical medicine. Boston/Toronto: Little, Brown \& Co.; 1985.

17. Peter LJ, Hull R. The Peter Principle. London. William Morrow \& Co.; 1969.

18. Okello D, Chongtrakul P. A manual for research priority setting using the ENHR strategy. Geneva: The Council for Health Research for Development; 2000. (COHRED Document 2000.3).

19. Gagliardino JJ, de la Hera M, Siri F. Evaluación de la calidad de la asistencia al paciente diabético en América Latina. Rev Panam Salud Publica 2001;10:309-317.

20. Navarro PR, Silva MS, Henao LH, Nunez MJ. Evaluation of an infectious disease service. In: White KL, ed. Health services research: an anthology. Washington, D.C.: Pan American Health Organization; 1992. Pp. 887-892. (Scientific Publication No. 534).

21. Selwyn BJ, Chavez MR. Coverage and patterns of ambulatory medical care use in Tlalpan, Mexico City. Soc Sci Med 1985;21:77-86.

22. Cousens SN, Mertens TE, Kirkwood BR, Smith PG, Feacham RGA. Case-control studies of common childhood diseases: the example of diarrhoea. London: MacMillan Education Ltd. for the World Health Organization; 1995.

23. Barcelo A, Daroca M, Ribera R, Duarte E, Zapata A, Vohra M. Diabetes in Bolivia. Rev Panam Salud Publica 2001;10:318-323.

24. Hamilton P, Diggory P. The Caribbean Epidemiology Centre (CAREC). Bull Pan Am Health Organ 1979;13(2):187-194.

25. Roussel PA, Saad KN, Erickson TJ. Third generation R\&D: managing the link to corporate strategy. Boston: Harvard Business School Press; 1991.

Manuscript received 16 August 2001. Revised version accepted for publication 26 February 2002. 
RESUMEN La investigación se puede considerar como un examen riguroso para profundizar el conocimiento y mejorar las prácticas. Una comisión internacional ha sostenido que el fortalecimiento de la capacidad de investigación es una de las formas más poderosas, eficientes y sostenibles de hacer progresar la salud y el desarrollo. Sin embargo, los esfuerzos mundiales para promover la investigación en los países en desarrollo han sido guiados sobre todo por la política y, en gran parte, por iniciativa de organismos donantes de los países desarrollados. Aunque esencial, este enfoque político es complementario de y al mismo tiempo contrasta con el de los gestores de la investigación, que deben fortalecerla "sobre el terreno", en servicios de salud que varían mucho según el país, y con mandatos, recursos y limitaciones muy diferentes. El concepto de investigación de las organizaciones sanitarias es amplio y las prácticas son muy variables. Sin embargo, la formación de la capacidad de investigación no es muy diferente de la formación de otros tipos de capacidad organizativa y tiene dos grandes aspectos: el estratégico y el operativo. En las organizaciones del campo de la salud, la creación de una capacidad de investigación importante se hace mucho más difícil cuando no se menciona la investigación en el enunciado de su misión. Capacidades de investigación que tardan años en crearse pueden ser fácilmente dañadas por un apoyo insuficiente, una mala gestión u otras influencias negativas internas o externas. Este artículo se basa en documentos clave sobre la política internacional de investigación y en observaciones sobre el comportamiento de los organismos donantes y de los organismos de investigación en relación con los países en desarrollo. Se analizan la formación de la capacidad de investigación, fundamentalmente como un reto para los gestores, los hechos reales detrás de la eficacia y la eficiencia operativas, los métodos de movilización de recursos y la necesidad de la empresa de investigación de realizar actividades de mercadeo, y se presentan algunos ejemplos del sur de Asia, América Latina y el Caribe.

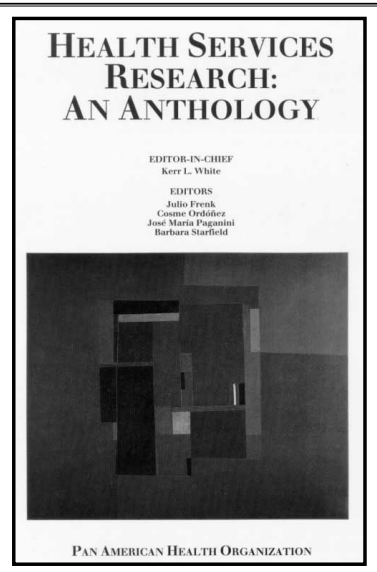

$1992 \cdot 1108 \mathrm{pp}$

ISBN 9275115346

Code: SP 534

Price: US\$ $40.00 /$

US\$ 30.00 in Latin America and the Caribbean

\section{Health Services Research: An Anthology}

This publication attempts both to illustrate the development of health services throughout the 20th century, especially in the Americas, and to provide a selection of some of the most representative articles on the various topics covered in the health services research literature. Because health institutions and services need improvements in various respects, many of the articles included in this volume deal with the equity, efficacy, effectiveness, and quality of health services. Others expound quantitatively on the development or application of appropriate research methods. Still others made, at the time they were published, significant contributions to an understanding of the policies, organization, and practice of health services.

The 100 articles in this collection will prove instructive and valuable to scientists, health policy makers, providers and consumers of health services, as well as to students of the field.

También disponible en español: Investigaciones sobre servicios de salud: una antología ISBN 927531534 5 Código: PC 534• Precios: US\$ 40.00 / US\$30.00 en América Latina y el Caribe 